DOSSIER:

\title{
Otras antropologías y otras historias de la antropología argentina
}

RMA

Dossier

Rosana Guber

CONICET, Instituto de Desarrollo Económico y Social, Buenos Aires.

E-mail: guber@arnet.com.ar

Es interesante que mucha gente no supiera definir lo que yo hacía: Cortazar decía que NO era folklore, compañeros que leyeron en público el informe sobre poblamiento, que era cualquier cosa pero que NO era antropología; Palavecino: que primero tenía que arrastrarme antes de volar; algunos otros que mis cosas eran una mezcla de sociología, geografía humana, historia; otros más audaces hablaban de antropología aplicada, etc.etc. I.../ Pero quiero reiterar mi desapego a que me incluyan como miembro de la comunidad de antropólogos académicos. Mi decisión fue en su momento, bien pensada y meditada: tratar de hacer algo que no sabía muy bien qué era, pero sí sabía que no tenía que hacer lo que hacen los académicos (Bilbao 2003, comunicación personal).

Pese a todo, Santiago Bilbao se había graduado con la primera cohorte de licenciados en ciencias antropológicas de la UBA en 1963. Sus caminos lo llevaron desde las comparsas del carnaval porteño hasta los obrajes del Chaco, los migrantes santiagueños y los "obreros-dueños" de la cooperativa de Campo de Herrera en Tucumán, hasta que se radicó en Venezuela y colaboró con productores de papa y de banano, para terminar escribiendo sobre los tramos argentinos de dos antropólogos extranjeros: Alfred Métraux y Roberto Lehmann-Nitsche. La decisión de su "desapego" a quedar encuadrado en alguna clasificación académica, muy propia de una personalidad inexorablemente comprometida con la práctica social y el trabajo de campo, que para él eran sinónimos, fue una de las tantas opciones que tomaron los antropólogos y otros cientistas sociales en los años 60-70. Esa opción encierra, como todo lo que él hizo, una cantera de sentidos que una antropología de la antropología está en condiciones de exhumar.

Las historias que los antropólogos argentinos hemos labrado de nuestra disciplina, suponen que este métier estaba de algún modo prefigurado y que, tarde o temprano, terminaría por revelarse y establecerse, y eso pese a los embates de la política nacional con sus proscripciones y prescripciones en el medio universitario. En las investigaciones que llevamos a cabo quienes integramos el proyecto "Antropología social e histórica del campo antropológico en la Argentina, 1940-1980"1 nos proponíamos explorar algunas conexiones entre personas, instituciones, prácticas e ideas relativas a lo que hoy entendemos como "antropología" aunque sin imponerles adscripciones previas ni recorridos teleológicos. En contextos donde definirse o ser definido como progresista, funcionalista, imbelloniano, marxista, antropólogo social, etnólogo, suele ser el punto de partida para comprender los modos en que los antropólogos fuimos comprendiendo las alteridades argentinas, nos parecía más fructífero entender esos rótulos como sistemas clasificatorios emprendidos por conjuntos sociales que hoy identificamos, incluso en la mirada retrospectiva, como propiamente académicos. En efecto, los procesos que conducen a afiliaciones teóricas no serían muy distintos de los que llevan a las diferenciaciones profesionales de las cuales la antropológica es sólo una posibilidad.

Si admitimos que la antropología es un producto cultural y que por lo tanto su existencia no era inexorable ni necesaria, el hecho de su aparición se torna una extraordinaria fuente de problemas de investigación. Es cierto que esta cuestión ya ha sido tratada por varios autores como Pierre Bourdieu, Bruno Latour, Steve Woolgar, Steven Shapin, George Stocking, y que en la antropología argentina los fundacionales trabajos de Irina Podgorny, Susana García, Leonardo Fígoli (aún inédito) y el mismísimo Santiago Bilbao, se ubican precisamente en el período en que algunas personas, generalmente ligadas a museos y universidades, empezaron a designar a sus búsquedas como "antropología".

Esas búsquedas tuvieron distintas locaciones, objetivos e inspiraciones que no se limitaron a un "período heroico" o inicial, ni forjaron a la antropología argentina de una vez y para siempre. Los artículos de este dossier muestran que quizás por imperio de nuestra turbulenta historia política e institucional, muchas personas debieron refundar constantemente aquello que entendían por "antropología", disciplinarse a sí mismas y a sus colegas, establecer criterios para reproducir esos disciplinamientos, y lograr un lugar siempre difícil en la panorámica de las ciencias sociales y las humanidades. Y al hacerlo se vieron confrontados con una condición de doble informalidad o, mejor dicho, intersticialidad que es inherente a quienes nos decimos o nos sabemos "antropólogos": porque lo intersticial es un rasgo de nuestros objetos

\footnotetext{
1 PICT/R 1728 (IDES-UNQ-UNC-UNICEN (Olavarría)-UNMDP) 2008-2011. Dirección: Rosana Guber. Investigadores: Mirta Bonnín, Gastón Gil, Andrés Laguens, Rolando Silla y Germán Soprano; becarios: Sergio Carrizo, Belén Hirose, Paula Macario, Susana Luco.
} 
de estudio, y porque nuestras prácticas investigativas y formativas radican poderosamente en formatos informales. La antropología no se practica ni se reproduce sólo en el aula ni en los libros y, pese a lo aseverado por Clifford Geertz, la escritura y luego la publicación, es tan solo una parte que, probablemente, no sea tan crucial.

Este dossier contiene artículos que exploran los intersticios de la antropología argentina en sus múltiples locaciones, agentes y posicionamientos. Mariela Zabala y Sergio Carrizo analizan el ingreso al campo antropológico establecido, de personas no tituladas ni consagradas en él: Monseñor Pablo Cabrera, en Córdoba, y Radamés Altieri en Tucumán. Gastón Gil y Mirta Bonnín exploran las radicaciones conflictivas de teorías y prácticas que no condecían con el establishment académico nuclear de Buenos Aires y La Plata: la ecología cultural de Julian Steward y la arqueología social de Osvaldo Heredia. Belén Hirose busca la consagración de ese establishment en el folklore como ciencia y como práctica nacionalizadora, con la obra de Carlos Vega y la formalización de la danza folklórica desde Buenos Aires. Susana Luco analiza la intervención de Carlos Aschero en los inicios de la transformación paradigmática de la arqueología patagónica porteña desde la escuela histórico-cultural a la new archaeology cuando, supuestamente, nada podía modificarse desde el interior de las instituciones. Y Germán Soprano muestra los recursos formales e informales con que contaron dos importantes antropólogos en la gran institución platense del Museo de Ciencias Naturales y Antropología: Eduardo Mario Cigliano y Alberto Rex González.

Cada uno de estos trabajos hace, desde su respectiva temática, época y contexto, al menos tres contribuciones que consideramos importantes porque cuestionan el sentido común que los académicos reproducimos en nuestras rutinas cotidianas y en nuestra reconstrucción historiográfica. Una es que la construcción de lo que hoy entendemos por "antropología" en la Argentina no depende sólo, ni principalmente, de definiciones teóricas generales, sino de personas concretas que en todo caso realizaron una ardua labor para poner las teorías disponibles en diálogo con sus campos empíricos y prácticas metodológicas y técnicas. Podemos así encontrar la apropiación y radicación de teorías o prácticas teóricas producidas en un punto de la metrópoli académica, como sucedió con la ecología cultural de Steward y la arqueología francesa de Sonneville Bordes (Bonnín, Gil, Luco, Soprano), e inversamente, podemos encontrar a quienes llevaron sus investigaciones empíricas al mundo académico y con ellas llegaron a consagrarse en él (Carrizo, Hirose y Zabala).

La segunda contribución de este dossier es que los autores analizan la práctica docente establecida como ámbito de expresiones diversas: teóricas y metodológicas, disciplinares, intradisciplinares y político-ideológicas. Pero una vez más, el término "docencia" no es unívoco. Un mismo autor puede ser enseñado y citado formalmente (Carrizo), puede ser el inspirador silencioso de un programa (Gil, Soprano), o puede ser contestado y reelaborado según las circunstancias de la práctica investigativa o de los requerimientos de la coyuntura (Bonnín, Hirose, Luco). Dos profesores pueden abrevar en bibliografías similares para enseñar materias distintas y expresar prácticas diversas de investigación (Luco, Soprano).

La tercera contribución es que los autores se han encontrado con perfiles que no caben en moldes establecidos de la práctica académica tal como la concebimos hoy en la antropología argentina. Un sacerdote ingresa a la academia de la americanística para subordinarse a la lógica científica racionalista, no para exorcizarla (Zabala). Osvaldo Heredia, discípulo del insigne arqueólogo Alberto Rex González, lleva su ideología radicalizada a reformular las premisas que ha aprendido con su maestro (Bonnín). Un delfín de la escuela histórico-cultural como Carlos Aschero, sienta las bases metodológicas y sobre todo, la posibilidad de pensar la arqueología de Patagonia por otros carriles que sus profesores, jefes y directores de investigación (LuCo). Y un personaje pretendidamente académico como Vega, "simplifica" una danza anónima con el fin de adaptarse a formatos escolares, contribuyendo así a la transmisión del saber popular y nacional (Hirose).

Los antropólogos enseñamos en nuestras clases, nuestros escritos e incluso en nuestros trabajos de campo, que nada es lo que parece, aunque lo que parece no carezca de importancia; enseñamos que las personas están determinadas sociocultural e históricamente, pero que sus márgenes de agencia son enormes comparados con los que solemos asignarles estructuralmente; y enseñamos que las otras institucionalidades que alguna vez sólo estudiamos en los pueblos no occidentales, también habitan las formas institucionalizadas del mundo académico y antropológico. Sistemas de reciprocidad, clasificación y disciplinamiento no se limitan a los Otros. El desapego de Santiago Bilbao por las clasificaciones académicas, no es sólo una expresión de disconformidad propia de su tiempo; es además un modo profundamente antropológico de llevar un quehacer que él aprendió en la academia, a los campos que quiso conocer y contribuir a cambiar. Todos los protagonistas de los artículos de este dossier tuvieron intenciones de mejorar las realidades que conocieron, las sociales y las académicas. Bucear en lo que fueron para ellos sus emprendimientos y proezas, es también empezar a reconocer las particularidades de cada época, los contornos y originalidades de nuestros anclajes locales; en suma, es advertir en aquella cantera nuestras propias y muy antropológicas diversidades².

\footnotetext{
${ }^{2}$ Agradezco la colaboración de Andrés Laguens y Rolando Silla, a pulir las articulaciones contenidas en este dossier, y el trabajo inspirador de algunas ideas de este prólogo, de Paula Macario.
} 